\title{
Nurses' Perception of Pain in People With Dementia: A Philosophical Overview
}

\author{
Mohammad Rababa ${ }^{1} \&$ Baker M. Bani-Khair ${ }^{2}$ \\ ${ }^{1}$ School of Nursing, Jordan University of Science and Technology, Irbid, Jordan \\ ${ }^{2}$ Department of English, Hashemite University, Jordan \\ Correspondence: Mohammad Rababa, School of Nursing, Jordan University of Science and Technology, P O Box \\ 3030, Irbid 22110, Jordan. Tel: 962-2-720-1000. E-mail: mjrababa@just.edu.jo
}

Received: April 23, 2018 Accepted: May 29, 2018 Online Published: June 11, 2018

doi:10.5539/gjhs.v10n7p160

URL: https://doi.org/10.5539/gjhs.v10n7p160

\begin{abstract}
Pain perception is a very complicated phenomenon in dementia care. Both rationalists and empiricists strived to reach to an understanding of pain perception. Rationalists such as Plato, Aristotle, and Descartes made some contributions in knowledge development of the concept of pain perception. Empiricists discussed how sensory experience, evidence based practice, tradition, and systematic approach of thinking could affect the knowledge attainment of pain perception. Nurse researchers would investigate both philosophical traditions in order to have comprehensive understanding of pain perception and facilitate nurses' decisions to treat pain in people with dementia.
\end{abstract}

Keywords: pain perception, rationalism, empiricism, people with dementia, nurse

\section{Background}

Pain perception is a complex topic of inquiry that can be studied in terms of miscellaneous disciplines of knowledge. One of these disciplines which helps to understand the inquiry of pain is philosophy (Bridges, 2016). Since ancient times, people have sought to study and analyze the concept of pain perception. They had been thinking about the origin and nature of pain, but they have always attributed it to sharp feelings (Sternbach, 2013). Pain perception has been of great concern to nurses. The challenge for nurses to understand pain perception relates to the vague nature of this term. This complex subject has been studied for decades and, unfortunately, a consensus has not been achieved regarding its essence. The complexity of pain perception as a philosophical argument has been quite controversial to many prominent philosophers and thinkers in different nations, historical phases, and various time periods across centuries. Therefore, it is quite noticeable that pain as a perception has been viewed differently by many philosophers, especially rationalists and empiricists. They proposed different approaches and methods to understand pain as a conceptual framework.

The most challenging thing for nurses in the care-providing process to the People With Dementia (PWD) is to understand the perception of pain experienced by patients as to feel and recognize their sense of pain, especially because this category of patients have verbal impediments that hinder them from verbally and orally expressing their feelings about pain degree and level of suffering. These difficulties, in fact, arise from mental and cognitive impairments that affect their true understanding of the self as a conscious process. Pain perception is a very complicated phenomenon in dementia care. The major problem here is that pain in people with dementia is still underestimated and marginalized, thus it continues to challenge nurses (Kovach, 2013). Basically, the manifestations of pain in PWD can be assessed in different ways such as observing odd behaviors or mood changes. However, the interpretation of these manifestations may be difficult for nurses. Therefore, there is a possible chance for these people to be misdiagnosed and for their pain level to be over- or underestimated, and consequently, not given the right attention and treatment (Gilmore-Bykovskyi \& Bowers, 2013). The gold standard of pain diagnosis is verbal self-reporting, but it is not possible in case of people with advanced dementia (Booker \& Herr, 2016).

The nursing literature provides a plethora of definitions of pain. Pain in nursing is defined as "a complex, multidimensional phenomenon that originates from sensory stimuli, which has obvious motivation-affective properties, demands attention, disrupts thought and behavior and results in activity aimed to stop the pain" 
(Blanchard, 2010, p. 138). In respect to dementia care, pain is defined as "an uncomfortable, subjective experience that can be communicated to others when possible through reporting or through a number of pain-related signs" (Karlsson, Sidenvall, Bergh, \& Ernsth - Bravell, 2013, p. 1881). Nurses' perception of pain in PWD comes from their perception of human values, which is the core of nursing science. According to Karlsson et al., as an alternative way to assess the perception of PWD to their pain level, nurses can refer to their own perception and experience of pain to get a clear understanding of the nature of their patients' pain. However, many nurses and physicians have misperceptions of the concept of pain (Rababa ${ }^{\mathrm{a}}$,2018; Rababa ${ }^{\mathrm{b}}$,2018). This critique will acknowledge the strengths and limitations as derived through consideration of alternative viewpoints about the concept of pain perception. Also, the likely areas of disagreement in these two philosophical traditions will be highlighted in details.

\section{Rationalism and Pain Perception}

Classical philosophy made some contributions in knowledge development of the concept of pain perception. Plato's contribution to the concept of pain perception was in his efforts to make a clear distinction between false and real pain. Plato's perspective of pain perception was unconventional and non-traditional as it went against what was known at that time as a common belief when people did not question the reality or nature of pain (Moayedi, \& Davis, 2013).

\subsection{Aristotle and Pain Perception}

Aristotle, for example, is frequently remembered for his development of logic, syllogism. He believed in using a combination of inductive and deductive reasoning to avoid drawing false conclusions from observation alone. He thought that inductive reasoning alone, which means generating conclusions from observation of particulars, was inadequate in knowledge development (Aristotle, 1947). Aristotelian principles, approaches, and methods were based on logical and keen observations and deductions. He did not rely on traditional methods for pain diagnosis and treatment; rather he relied heavily on logical perception. In light of this, it is not sufficient for nurses to refer to clinical observations about pain perception of their patients in order to develop adequate knowledge about this concept, but a case should be studied thoroughly using a systematic and logical analysis.

Aristotle did not believe in intuition alone, instead he emphasized that knowledge must be acquired scientifically or through deduction. This is consistent with the ability of a nurse attained through knowledge and long experience, to predict the presence of pain in PWD despite a relatively small or no amount of information disclosed by afflicted patients. The nurse can use his/her intuition to gain knowledge about pain perception of patients, which may come through observing a specific unusual behavior or symptom. Aristotle combined perception and logical reasoning to generate knowledge (Rodger, 2005). This implies that nurses need to use their perceptions and logical reasoning to generate knowledge of pain perception of their patients.

Aristotle used both sensory and non-sensory data as contributors to the development of knowledge (Rodger, 2005). Thus, sensory and non-sensory data are needed to assess and measure pain perception in humans. Consciousness and awareness are considered strength points in nursing and care-providing because they can help to reveal the real aspects of pain sensation if they are intuitively connected with keen reasoning of the studied case that varies in accordance with situations and conditions.

Aristotle believed that every problem had an objective solution. He seemed to believe if one could understand the cause and conclusion of what was being done, one is said to have scientific knowledge (Rodger, 2005). That thought could be applied to nursing fairly easily. To have an understanding of why individuals do things is to have the knowledge of it. In nursing, if nurses do things that they do not understand there is potential for injury instead of healing. To properly assess pain, nurses need to fully understand how their patients perceive pain.

According to Marks (2014), Aristotle did not consider pain as one of sense-qualities that can be perceived by the sense of touch. Aristotle argued that pain combined with pleasure is one of soul's passions. It is not surprising that people in ancient times perceived pain as a different form of senses or as the opposite of pleasure. Unlike the common senses, pain does not have a specific sense organ, and it is not limited to any part of the body as well, nevertheless it pervades the whole body. In addition, all qualities of the five senses are qualities of external objects, but pain is not and is likely to be inherently unpleasant. Pain can not be precisely measured only by using senses; pain might be an internal or external experience that might not relate to external objects alone. As a result of these considerations, in addition to what Aristotle had argued about the nature of pain, the perception of pain as a sense quality was too late. All these limited and traditional perspectives of pain had been dominant for a while in ancient times. 


\subsection{Descartes and Pain Perception}

Aristotle's work was clearly focused on differentiating induction from deduction as a possible approach to apply in nursing. According to Aristotle, induction alone is inadequate to develop knowledge about the concept of pain perception. For knowledge to be developed, all particulars of pain perception have to be examined(Rodger, 2005). For example, all aspects of pain perception should be addressed including physical, psychological, behavioral, and spiritual ones. Looking at pain experience as a holistic body can lead to accurate understanding of it, and therefore assessing and diagnosing it appropriately. Aristotle seemed to agree with Descartes in his views concerning sensory data. Descartes said, "to accept nothing as true"; this points to Descartes' idea of rationalism as one of his main contributions to modern science (Rodgers, 2005, p.44). Simply put, Descartes emphasized the power of thinking. He rejected empiricism or the collection of sensory data to be used to gain scientific knowledge. He did believe that sensory data can change so researchers cannot rely on this data to be true (Descartes, 1960). This implies that nurses cannot rely on sensory data to gain knowledge about pain perception of their patients. This is consistent with the critical thinking process that nurses use in their practice. However, nurses utilize sensory data on a daily basis to assess their patients' pain.

Descartes argued that even if people believe that they see something physically visible, there is no way you can truly be sure that it is real. He continued that the only thing that people can be sure of is that the mind exists. He justified this by saying that even if people perceive something to be true (e.g. wax) that it may not be what they really think it is. The fact that people are thinking about this wax, is what makes the mind real (Rodger, 2005). With applying this statement on the concept of pain perception, nurses can attain knowledge about the pain perception of their patients by using only their minds. Descartes' argument is limited because he did not address the fact that what people call reality is consistent and is a shared experience by all. The majority of people are not all having the same delusions, so what the majority believes to be true, is probably true. Believing that the mind is the only thing that people can believe is real does not apply to their daily lives. It does not matter if what people perceive to be true is a delusion or not, they have to deal with it regardless of its present nature.

Descartes is well known for his concept of real distinction, which suggests that the mind and body are unique and distinct from each other but a person must have both. Descartes' Mind/Body Dualism was incredibly essential to forward thinking at the time and so important to the development of nursing knowledge (Rodger, 2005). All nurses need to know that the mind/body principle applies to almost everything they do and experience with patients, from the experience of pain, coping with a new treatment plan, and end of life issues as examples. It supports the whole person care of nursing. Descartes offered nurses a great start in the dualism of mind and body, but his actual knowledge of the functioning of the brain was limited by the lack of scientific and experimental knowledge at the time. It is fascinating that he thought the pineal gland was the portal between the mind and the body because it is a unique, single organ in the brain (Rodger, 2005). According to Descartes' view about real distinction between the mind and body, the potential cause for pain must be physically measured and observed. So, he denied the other causes of pain that may be related to something psychosocial, behavioral, or spiritual. As a result, although it had been a long time since Descartes' argument was established, it was impossible to treat pain without presenting signs of organic disease. All patients who have this kind of pain were labeled as "crocks" in the 1950s (Melzack, 1993). The goal of nursing is to provide holistic care for individuals where patients are viewed as a whole entity. From that perspective, the individual is viewed as composed of not only body and mind, but spirit as well. In order for nurses to practice holistic nursing, and to better achieve a comprehensive care of pain for people with dementia, it becomes quite essential for nurses to understand all dimensions of pain.

Descartes' perspective of body-mind causes a major revolution in knowledge of pain perception development. Descartes argued that the human body is similar to a machine. This argument helps experimental methods to study the anatomy and physiology of pain. After many experiments, researchers were able to figure out pain pathways and the pain center inside the body. As a result, much chronic severe pain can be treated through neurosurgical procedures (Melzack, 1993). Also, Descartes established the theory of pain, which was applied until the 20th century. Actually, he was the first philosopher who was influenced by the scientific approach to think. Since Descartes' time, there have been many theories developed about the concept of pain. All theories, which are proponent to Descartes' view of pain, are labeled "pattern theories" (Melzack, 1993). Peterson and Bredow (2009) credited Descartes with the first explanation of pain theory in his pulling of a boy whose foot was too close to a fire. The current understanding of pain sensory transmission pathways in the human body has come a long way from the 17th century drawing by Descartes (Smith \& Liehr, 2013).

According to Zalta, Nodelman, Allen, and Perry (2011), the common sense conception of pain can be 
summarized in the following two threads. First, pain is a physical object that can be characterized by its location, volume, and intensity. For example, someone can say "I feel sharp pain in the left side of my head". Second, pain is a subjective unpleasant sensory and emotional experience, which is caused by actual or potential tissue damage. Comparing the two threads with each other, it is apparent that the second thread seems to capture the dominant common-sense conception of pain. Most physicists believe that pain experiences are located in the head, namely the brain or the central nervous system if they are anywhere. Although the first thread describes pain as a particular condition of a certain body part, it does not define that particular location. As shown from the example above, the statement indicates that pain was felt in a bodily location without committing to there being anything physically wrong in that location (Zalta et al., 2011).

\section{Empiricism and Pain Perception}

According to empiricism, nursing inquiry uses experiences for knowledge attainment, perhaps not in the strict sense of sensory experience, but in the actual experiences themselves. In other words, empiricism includes the use of reflection and experiences for knowledge attainment in nursing (Rodger, 2005). Reflection on lived experiences creates a sense of knowing. Also, empiricism highlighted practice based evidence, which is the process of reflecting on one's experiences in nursing and what knowledge can be gained from them (Rodger). To attain knowledge about pain perception, nurses need to refer to their experiences of pain in order to fully perceive and properly interpret their patients' pain. Also, they can refer to their experiences of assessing and managing their patients' pain that happened in the past to properly perceive and interpret pain. In order to get a clear understanding of pain perception, it is crucial to focus on experiences either from their patients' point of view, or their students' experiences during the learning process, or most importantly from the experiences of patients' sensations of pain through interventions and treatments.

Empiricism emphasized the systematic approach to the attainment of knowledge (Rodger, 2005). Empiricism emphasized the important role of sensory experience through the physical world. It further emphasized evidence. Sensory data play a very important role in nursing, especially in nursing research (Rogers, 2005). Nurses observe the objective data about patients' pain and gather this information to develop basic ideas about their patients' perception of pain to which they further reflect upon. This reflection gives them more complex ideas and knowledge that develop into theories. One of the premises of empiricism is that theory and hypotheses should be tested through observation of the physical world (Rodger, 2005). This is a cornerstone of the scientific method used today in nursing discipline.

Empiricism also discussed how tradition could impede knowledge attainment, which is something that nursing continues to struggle with (Rodger, 2005). The statement "because we have always done it this way" is still said by many practitioners. For example, some nurses have many stereotypes or misconceptions about pain perception in people with dementia. Since nurses are unable to understand or interpret the experience of pain in people with dementia, they think that people with dementia do not feel pain or they do not care about their pain. This is definitely not true. The prevalence of painful conditions in persons with and without dementia is similar (Haasum, Fastbom, Fratiglioni, Kareholt, \& Johnell, 2011; Rababa ${ }^{\mathrm{a}}$, 2018; Rababa ${ }^{\mathrm{b}}$, 2018).

\subsection{Locke and Pain Perception}

Locke is an extreme empiricist. He demonstrated in his writings an intense need to counter Descartes position of innate ideas, which required him to come up with his own origin for knowledge. He argued that all knowledge comes from sensory experiences (Locke, 1975). With respect to pain perception, people need to have an experience of pain first to come up with the knowledge of pain perception. He also believed that the mind is a blank slate from the beginning, and knowledge is formed through experience and the formation of ideas, from simple to complex (Rodger, 2005). This is actually consistent with how the knowledge of pain perception has been developed or built up. It started with a simple idea and then has been developed to complex idea over time. Locke argued against Descartes' central premise of innate ideas present in the mind. He viewed the mind as a white paper or a blank slate that receives the first sensation and subsequent sensations or experiences (Rodgers). This implies that once a person has an experience of pain, there is a reflection period when the mind is engaged in idea formation. These experiences generate simple ideas that are compared and contrasted then formed into complex ideas. The complex ideas then lead to the development of knowledge of pain perception. Reflection involves a more internal process whereby there is discovery into the workings of a one's own mind as defined by perceiving, thinking, and reasoning.

Locke discussed the concept of pain perception to verify and assert his view of happiness perception (Locke, 2007). He argued that happiness is similar in its meaning to pleasure, but unhappiness equals pain. He continued to say that the differentiation between false and true pleasures is that false pleasures produce an immediate sense 
of enjoyment but it causes long-term pain whereas true pleasures causes a strong and sustained sense of happiness. He concluded with a general statement; the sense of happiness depends on the person's experience of pain. Lock also agreed with Descartes on his view of pain in respect to the existence of the self. Lock argued that I think, I reason, I feel pleasure and pain. In order to get a clear understanding of his perspective, he always refers to his logical analysis of the notion that "if I know I feel pain, it is evident I have as certain perception of my own existence, as of the pain I feel: or if I know I doubt, I have ascertain perception of the existence of the thing doubting, as of that thought which I call doubt". One of the most important components of Lock's argument is that pain is accompanied by the sensation, and is absent from the notion as it repeats in memory (Locke, 2007).

One principle of empiricism that is integral to nursing practice is that all knowledge should be generated for a purpose and for the common good of the people. With respect to pain perception, empiricists view that nurses exist in the hope of helping others, whether their pains are physical, emotional, mental, or spiritual in nature. Nurses exist to elevate the human condition at all levels. Therefore, the future trend to properly address the concept of pain perception in people with dementia is addressing all pain dimensions: physical, psychological, behavioral, and spiritual together in one assessment model to obtain more comprehensive pain-assessment protocol. The classic definitions of pain perception are inappropriate when applied to people with dementia. In addition, the indicators of pain are unclear for them and pain instruments are ineffective in evaluating their pain. In order to address all these issues, a multidimensional conceptual model of pain perception is recommended.

\section{Conclusion}

Nurse researchers would use these different philosophical traditions to examine pain perception in nursing. Both rationalism and empiricism have a great influence on the development of the concept of pain perception. Both rationalists' and empiricists' thought have a profound influence on the critical thinking process, which nurses use in their practice to understand their patients' perception of pain experience. A combination of two traditions might lead to a more comprehensive understanding and facilitate nurses' decisions to treat pain in nursing home residents with dementia. Further examination and evaluation of the concept of pain perception might help nurses gain more knowledge about the concept. This knowledge can contribute positively in improving nursing discipline and practice.

\section{Competing Interests Statement}

The authors declare that they has no competing or potential conflicts of interest.

\section{References}

Aristotle. (1947). Posterior analytics (G. R. G. Mure, Trans.). In R. McKeon (Ed.), Introduction to Aristotle (pp. 5-109). New York: Modern Library.

Blanchard, J., \& Murnaghan, D. (2010). Nursing patients with acute chest pain: practice guided by the Prince Edward Island conceptual model for nursing. Nurse Education in Practice, 10(1), 48-51. https://doi.org/10.1016/j.nepr.2009.03.010

Booker, S. Q., \& Herr, K. A. (2016). Assessment and measurement of pain in adults in later life. Clinics in Geriatric Medicine, 32(4), 677-692. https://doi.org/10.1016/j.cger.2016.06.012

Bridges, D. (2016). Philosophy in Educational Research: Epistemology, Ethics, Politics and Quality. Springer. https:///doi.org/10.1007/978-3-319-49212-4

Descartes, R. (1960). Meditations on first philosophy (N. K. Smith, Trans.) In M. C. Beardsley (Ed.), The European philosophers from Descartes to Nietzsche (pp. 25-96). New York: Modern Library. (Original work published 1641).

Gilmore-Bykovskyi, A. L., \& Bowers, B. J. (2013). Understanding nurses' decisions to treat pain in nursing home residents with dementia. Research in Gerontological Nursing, 6(2), 127-138. https://doi.org/10.3928/19404921-20130110-02

Haasum, Y., Fastbom, J., Fratiglioni, L., Kareholt, I., \& Johnell, K. (2011). Pain treatment in elderly persons with and without dementia: A population-based study of institutionalized and home-dwelling elderly. Drugs \& Aging, 28, 283-293. https://doi.org/10.2165/11587040-000000000-00000

Karlsson, C., Sidenvall, B., Bergh, I., \& Ernsth - Bravell, M. (2013). Certified nursing assistants' perception of pain in people with dementia: a hermeneutic enquiry in dementia care practice. Journal of Clinical Nursing, 22, 1880-1889. https://doi.org/10.1111/jocn.12197 
Kovach, C. R. (2013). Assessing pain and unmet need in patients with advanced dementia: the role of the Serial Trial Intervention (STI). In Handbook of Pain and Palliative Care (pp. 131-144). Springer New York. https://doi.org/10.1007/978-1-4419-1651-8_10

Locke, J. (1975). An essay concerning human understanding (P. H. Nidditch, Ed.). Oxford: Oxford University Press. (Original work published 1689).

Locke, J. (2007) In Internet Encyclopedia of Philosophy. Retrieved from http:// http://www.iep.utm.edu

Marks, L. E. (2014). The unity of the senses: Interrelations among the modalities. Academic Press.

Melzack, R. (1993). Pain: past, present and future. Canadian Journal of Experimental Psychology, 47, 615-629. https://doi.org/10.1037/h0078871

Moayedi, M., \& Davis, K. D. (2013). Theories of pain: from specificity to gate control. Journal of Neurophysiology, 109(1), 5-12. https://doi.org/10.1152/jn.00457.2012

Peterson, S. J., \& Bredow, T. S. (2009). Middle-range theories: Application to nursing research. City: Wolters Kluwer Health.

Rodgers, B. L. (2005). Developing nursing knowledge: Philosophical traditions and influences. Philadelphia, PA: Lippincott, Williams \& Wilkins.

Rababa, M. (2018). Pain Assessment in People with Dementia: Remaining Controversies. Global Journal of Health Science, 10(5), 62-69. https://doi.org/10.5539/gjhs.v10n5p62

Rababa $^{\mathrm{b}}$, M. (2018). The association of nurses' assessment and certainty to pain management and outcomes for nursing home residents in Jordan. Geriatric Nursing, 39(1), 66-71. https://doi.org/10.1016/j.gerinurse.2017.06.015

Smith, M. J., \& Liehr, P. R. (Eds.). (2013). Middle range theory for nursing. Springer Publishing Company.

Sternbach, R. A. (2013). Pain: A psychophysiological analysis. Academic Press.

Zalta, E. N., Nodelman, U., Allen, C., \& Perry, J. (2011). Stanford encyclopedia of philosophy. Palo Alto CA: Stanford University.

\section{Copyrights}

Copyright for this article is retained by the author(s), with first publication rights granted to the journal.

This is an open-access article distributed under the terms and conditions of the Creative Commons Attribution license (http://creativecommons.org/licenses/by/4.0/). 